every science came when, in the study of problems which were modest as compared with ultimate aims, methods were developed which could be extended further and further. The sound procedure is to obtain first utmost precision and mastery in a limited field, and then to proceed to another somewhat wider one, and so on, until finally the field of real success is reached, that is, prediction by theory. The authors state that there is no reason why economics can expect any easier fate than that which befell other soiences such as physies and chemistry, and that it will not be possible to build up a complete mathematical theory for many years to come.

Having formulated the basic economic problems, the book now turns to the mathematics of games themselves. The mathematics are self-contained, in the sense that theory is developed from primitive ideas, but an extensive use is made of set-theory, and of course mathematical notation. Forty pages are spent in formulating the general description of a game, introducing all possible complications into the theory, and finally describing the game in terms of ten axioms. It is then shown that these can be reduced to three, the two definitions being rigorously equivalent. The two definitions are designated as 'Extensive' and 'Normalised' respectively, and it is sometimes found convenient to use one, and sometimes the other in the problems which follow.

The next chapter starts with a discussion of oneperson zero-sum games, for example, patience, then advances to zero-sum two-person games, the discussion being dominated by illustrations from chess, poker, bridge, etc., and not from cartels, markets, oligopolies. The theory now passes on to three-person zero-sum games. It is shown that whereas a oneperson zero-sum game is merely a simple maximum problem, the passage from a one-person zero-sum game to a two-person zero-sum game obliterates the maximum problem, and the game is designated by $\mathbf{a}$ clear-cut opposition of interest. Similarly the passage to the three-person zero-sum game obliterates the opposition of interest. Here independent coalitions may arise, and the relationships between two players may be manifold. The game can be reduced to three two-person zero-sum games.

The theory now advances to the $n$-person zero-sum games. Little penetration below the surface has been made, however, and the theory comes back to a discussion of the case $n=4$. Even here, however, the problem is soluble only in certain special cases. Some aspects of $n \geqslant 5$ are now considered, but the problem becomes so complicated that it seems rather hopeless to push this approach beyond $n=5$. On the other hand, it is absolutely vital to get some insight into the conditions which prevail for the greater values of $n$. Quite apart from the fact that these are most important for the hoped-for economic and sociological applications, there is also this to consider : with every increase of $n$, qualitatively new phenomena appeared. This was clear for each of $n=2,3,4$. It was not observed for $n=5$, but this may have been due to lack of detailed information about the case. It will appear later that very important qualitative phenomena make their first appearance for $n=6$.

For these reasons it is imperative that some technique should be evolved for the attack on games with higher $n$. In the present state of affairs nothing systematic or exhaustive can be hoped for. Consequently, the natural procedure is to find some special classes of games involving many participants which can be decisively dealt with. Two families of such special cases are then formulated and discussed, each considered as generalizations of four-person games.

The trend of the book now alters. The zero-sum restriction is dropped, and the theory comes into close contact with questions of the familiar economic type. After a short discussion of the general case which consists mainly of plausible arguments, an economic interpretation is given for $n=1$ and 2 and for a special case of $n=3$.

From the point of view of notation alone, it is doubtful whether anyone but a fairly competent mathematician would be able to follow the arguments put forward. This was unavoidable, but seems a pity as the book will remain closed to economists who are unfamiliar with mathematical ideas and methods.

E. Rowland.

\section{EVOLUTIONARY THEORIES OF ETHICS}

The Moral Theory of Evolutionary Naturalism By Prof. William F. Quillian, Jr. (Yale Studies in Religious Education, No. 17.) Pp. xiii+154. (New Haven, Conn.: Yale University Press; London: Oxford University Press, 1945.) 20s. net.

7 HIS is a careful, fair but completely devastating analysis of the evolutionary theories of ethics which were very fashionable towards the end of the nineteenth century and still have a considerable vogue. It deals mainly with the work of Darwin, Spencer, W. K. Clifford, Leslie Stephen, Guyau and Westermarck. Later writers do not appear to have produced any fresh arguments.

As Dr. Quillian insists, the evolutionary naturalists were undoubtedly right in asserting that man is a part of Nature, that his morals have evolved and that a process comparable to natural selection is at work. Their error was in saying there is nothing else and in smuggling the notion of obligation surreptitiously into what purported to be a factual account. Guyau and Westermarck, it is true, realized that earlier writers were confused about obligation, and professed to dispense with the notion. But had they really done so, they would have had no theory left. They only appeared to do it by a further confusion. Assertions of conditional obligation may be made to look entirely factual so long as the unconditional obligation on which they rest is not discussed. 'Over-eating causes illness' is an assertion of fact, from which the conditional obligation, 'I ought not to over-eat', can be derived, if 'I ought to keep well' is itself unconditional or else derived from some other unconditional obligation.

The evolutionary naturalist is liable to assume tacitly that mere survival is the one unconditional obligation, though whether of the individual or the race he is not clear; nor is he clear why we should pursue an aim that inevitably ends in frustration. $\mathrm{He}$ has no criterion to distinguish the life which is worth living, however short, from that which is not, however long.

The only criticism to be made of this book is that there is too much quotation for easy reading, and that the writing is uninspired. Can the evolutionist or anyone else explain why books on ethics are duller than other philosophical books?

A. D. Ritchie. 